\title{
Comentario al libro de Ricardo Falla, s. j.: Ixcán: El campesino indígena se levanta. Guatemala 1966-1982 (Tercer volumen de la colección Al Atardecer de la Vida)
}

\section{Tania Palencia Prado*}

La memoria es el infierno, dijo atrevido el gran señor Luis Cardoza y Aragón, cuando penetraba en las sombras inconclusas de sus recuerdos. Aquí en este foro, con un público que no quiere olvidar, estamos seguros de que la memoria no es el infierno (¿o sí lo es?). Lo cierto es que este libro recorre laberintos oscuros, silenciados, acallados, llenos de voces y almas con las bocas abiertas, como los caminos de sangre de Virgilio en $\mathrm{La}$ Divina Comedia. Ricardo Falla invita a hablar de lo no dicho, a discutir, a pensar, a gritar, a ser altoparlante de las utopías expulsadas, todo lo cual es saludable, máxime cuando, en Guatemala, la memoria comunitaria simplemente no se nombra, ni siquiera como infierno y, por tanto, no tiene existencia. No existe.

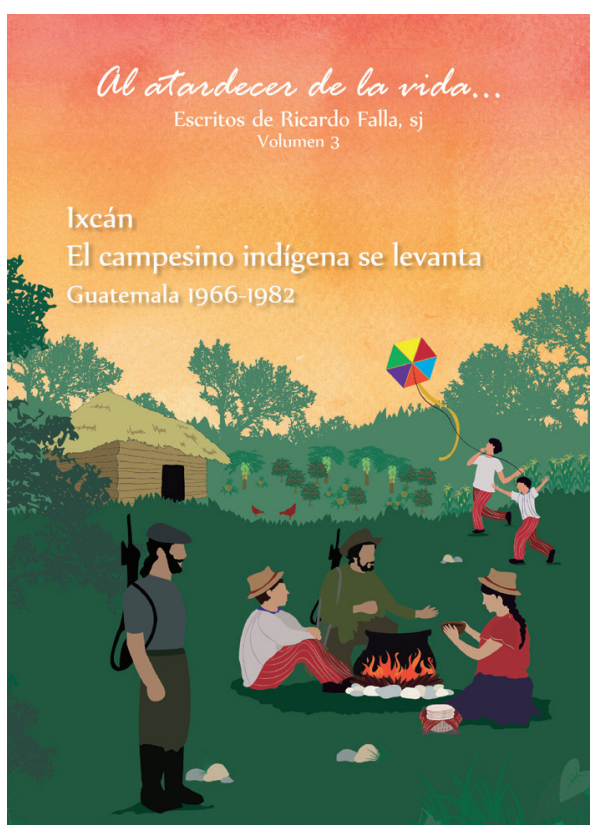

Hoy quiero bosquejar con ustedes cuatro asuntos del libro que me parecen de alta relevancia para vernos y cuestionarnos como sociedad: 
Contribuye a pensar una sociología de lo prohibido. Es notorio que el libro trasgrede y remonta con gran valentía los ejes del paradigma social dominante, como son, entre otros, la censura, el miedo, el silenciamiento de la vida cotidiana rural y la negación absoluta de las rebeldías sociales. Con solo ese enfoque global que se articula en sus páginas, el autor contribuye a la renovación del pensamiento social guatemalteco, porque da vida a lo negado. Enfrenta así esa racionalidad abusiva de la ciencia social oficialista que solo fija y permite un pensamiento monocultural, vencedor, que no tolera la diversidad de experiencias, y menos las experiencias de los de abajo.

Falla, por eso mismo, ofrece un aporte epistémico, porque produce conocimiento social mediante la articulación de las experiencias de los desposeídos. Con novedosas técnicas excava a la vez el pasado y el presente, articula los tiempos vividos, acude a la polifonía de voces, testimonia las relaciones de poder, diagrama las luchas sociales, convierte el recuerdo en fuente de pensamiento comunitario y ofrece escenas frescas de la lógica perversa que caracterizó a la colonización del Ixcán. Con todo lo cual dibuja, abre, aflora en nuestra mente la actoría social más censurada por los siglos de los siglos en este país: la de la rebeldía.

Con la farsa del proceso de paz, ya hemos comprobado que el sujeto político del cual habla Ricardo Falla - es decir, el campesinado indígena- solo es tolerado como víctima en un juzgado, o como el sufriente de las masacres (donde los medios de comunicación de masas destacan al sufriente y olvidan las masacres), o como el perdedor, el inferior, el ignorante, el manipulado, el improductivo local. El autor critica esa sociología de las ausencias y produce una sociología de la emergencia de la insurrección rural indígena campesina. ¿Cómo aporta eso a la antropología y a la ciencia social en Guatemala? Produciendo conocimiento social como interrogación ética, como insumo para cambiar la vida. No podemos dar cuenta científica de nuestro tiempo si no recuperamos y reconstruimos las luchas sociales por la libertad; y la indignación social, la indignación de cientos y miles de campesinos indígenas que querían potenciar sus economías, vivir en paz, con libertad, pero que debieron sublevarse porque les impusieron un control esclavizante. Dar cuenta de los saberes negados y dar cuenta del gran valor de rebelarse es, además, un aprendizaje que debe ejercitarse para reinventar la emancipación, dado que Guatemala es hoy más inequitativa que ayer.

Tal aprendizaje de la lucha por la libertad le haría bien a esta nación acallada, especialmente en los centros escolares de todos los niveles educativos, donde se recicla solo el pensamiento de la subordinación, muy citadino, cargado de racismo y de menosprecio por lo rural. Y haría mucho bien a los operativos ciudadanos y a los movimientos sociales, porque nos estamos olvidando de esas rebeldías, situados o buscando zonas de confort que nos enclaustran, que nos incitan a maquillar al actual Estado o que nos hacen creer que resistir es lo mismo que la libertad. El aporte científico de este libro, más allá de las diecinueve hipótesis que lo componen, es el análisis de la experiencia de las comunidades sublevadas, perfilando así su potencial liberador todavía inconcluso. 
No perder de vista la perversa máquina que hace efectiva la opresión. Otra de las perspectivas relevantes que aporta el libro para cuestionarnos como sociedad es que suma pruebas a otros importantes estudios que han dicho que el tipo de Estado que tenemos en Guatemala no tolera la ciudadanía. Es decir, si el lector quiere saber un poco más cómo fue la colonización del Ixcán, encontrará en medio de la selva fragmentos del conocimiento que el campesinado indígena tuvo de ese poder.

Las imágenes que Ricardo Falla nos muestra son precisamente las de un Estado hecho para reproducir el sistema de finca como única racionalidad para la economía nacional. Falla suelta muchos hilos sobre el Estado que invitan a reconstruir esa racionalidad, y esos hilos muestran la total ausencia de mecanismos reales y efectivos para potenciar la economía campesina. Muestran también la monstruosidad de un Estado que, como sistema, como lógica de dominio público, avaló la colonización de Ixcán como gran pretexto para facilitar la acumulación de capital trasnacional.

Nos hace pensar que esa colonización no nació para responder a las necesidades de la economía campesina, sino para oxigenar la movilidad de los seres humanos desechados por la tecnificación de los latifundios de exportación. Nos hace reparar en cómo el Estado nunca abrió brecha, sino que usó a la Iglesia (aliada recurrente) para liderar un proceso que en sí mismo no le interesaba. Lo que al Estado le interesaba era la gran Alianza para el Progreso que desde Estados Unidos requería territorios para realizar los negocios petroleros y controlar nuevas carreteras para el mercado continental. Ricardo Falla nos muestra que el origen de la institucionalidad pública para favorecer a la economía campesina estuvo marcado por el desarrollismo contrainsurgente. El modelo de sustitución de importaciones en este país nació militarizado. Con el libro volvemos a comprobar un continuum histórico: que la militarización es la única estrategia válida y estable para sostener y reciclar las contradicciones que provoca el modelo finquero dominante.

De allí que todo lo que iba a ser, ya no fue. Y si no fue no se debe estrictamente a causa de la guerrilla, sino porque el Estado no quiso ni fue capaz de ceder autonomías, de respetar modos de producción colectiva, de potenciar la "otra" economía. Falla recuerda al ejército metido en todo, controlando todo, hasta vigilando y desconfiando de sus propios aliados: leeremos del control sobre los sacerdotes que lideraron las migraciones, del control sobre el Instituto Nacional de Cooperativas (Inacop) y sobre los técnicos agrícolas, del control sobre las cooperativas, sobre las compras y las ventas de insumos agropecuarios, sobre el mercado, sobre los caminos. Nos hace un recorrido hasta el momento en que el ejército tiene la vida bajo las botas. Vislumbramos con exactitud que la vieja noción de "el pueblo como enemigo interno" no solo se aplica a esta historia, sino que es uno de los fundamentos constitucionales del Estado de Guatemala. Y así nos es más fácil comprender, hasta hoy día, por qué se evaporó con tanta prontitud toda la institucionalidad pública que se creó en la década de los setenta para la economía campesina.

Este libro ofrece aportes para conocer al Estado de Guatemala, pone al descubierto su naturaleza criminal. Muestra que es un Estado inepto, incapaz y sin ninguna voluntad para crear pactos sociales. El libro ilustra con claridad cómo el Estado funciona para controlar a la población, para reducirla, para doblegarla, y 
hace de la militarización la otra cara de la única economía que ha permitido, que es la economía del despojo.

¿Cuánto podemos aprender de las insurrecciones indígenas campesinas? Un tercer tema de alto interés en el libro es propiamente el complejo fenómeno de la insurrección. Nos invita el autor a revalorar el debate y la responsabilidad de remontar tanta opresión. ¿Cómo podemos reinventar nuestros caminos de emancipación? El libro ofrece insumos para no desperdiciar la experiencia y para que aprendamos de lo vivido. Es una crítica testimonial a toda política liberadora basada en la unilateralidad.

Este aprendizaje no es fácil. Los pueblos alzados fueron derrotados cruelmente y muchas heridas todavía no cicatrizan. Un hito para potenciar nuestros aprendizajes es no confundir la indignación y las acciones insurreccionales con las estrategias guerrilleras. Cierto es, todos lo sabemos y Ricardo Falla también lo escribe, que las estrategias guerrilleras se alimentaron de los levantamientos comunitarios, y que los levantamientos de la gente crecieron con las acciones guerrilleras. Pero es bueno percatarse de sus diferencias porque, en rigor, nunca fueron lo mismo, y Falla ayuda a ese análisis.

Reconocer esta diferencia implica revalorar la energía de sublevarse, e implica asimismo repensar métodos de disputa de poderes que no reproduzcan los grandes errores de las estrategias guerrilleras. "No hay que tirar al niño con todo y el agua sucia”. La gente tenía un horizonte de cambio, tenía ideas fuertes para mejorar sus vidas; debiéramos recuperar tal fenómeno. Y a la vez, aprender que no lograremos cambiar tanta opresión si desplegamos los mismos operativos de lucha insurreccional. Destaco tres reflexiones que el libro me provoca, las tres sobre graves infortunios en el despliegue de estas luchas:

Subsumir la indignación indígena-campesina en los operativos vanguardistas: los levantamientos fueron subordinados en general a operativos militares, donde por mala suerte o por incapacidad se perdió de vista un paradigma de cambio de la configuración social de Guatemala, y se terminó pensando solo en el ejército, perdiéndose así los saberes que pretendían reorganizar y potenciar la vida de los territorios.

Perder de vista el horizonte de lo nuevo por solo prefigurar derrotas del ejército, menospreciando la gran necesidad que reclamaba Guatemala: construir un nuevo orden de lo público, cosa que sin lugar a dudas todavía necesitan todas las comunidades rurales de esta nación. Ahora, tras haber hecho tan poco análisis de la experiencia, se menosprecia el desafío de disputar poderes, porque se cree erróneamente que el poder equivale a partidos políticos. Poco se ha discutido cuánto necesita este país otros engranajes públicos para dar forma y orden a una convivencia en paz, con otras instituciones, otros flujos y otras condiciones que nos permitan reinventar nuestras vidas.

Reproducir métodos opresivos en las luchas de liberación, especialmente métodos jerárquicos, caudillistas y androcéntricos, lo cual fue y es un contrasentido. Esos métodos disgregan y fragmentan, paralizan nuestro espíritu de libertad, nos vuelven incapaces de entrelazar cambios rurales y urbanos para dimensionar pragmáticamente los focos imaginados de lo nuevo, atendiendo y articulando 
los satisfactores de las necesidades diversas. Es seguro que Ricardo Falla, aun sin pretenderlo, nos concita a repensar nuevas estrategias de emancipación.

Reconocer a fondo la naturaleza plurinacional de Guatemala. El cuarto y último asunto que esbozo como un gran valor del libro es cuánto nos falta aprender de la indianidad en Guatemala, especialmente en la capital, en los cascos urbanos. En otras palabras, Ricardo Falla al reflexionar sobre esos quince años de colonización, muestra las voces que tienen un $\mathrm{ADN}$ histórico de rebeldía: los pueblos indígenas de Guatemala, que han sido y son sujetos históricos de las luchas de liberación. Para mí esto es lo mejor del libro: valorar la energía de las comunidades indígenas que retrotraen siempre a flor de piel su historia de rebeldía. La negación de la ciudadanía indígena es un eje rector del dominio en esta nación. Los grandes momentos de opresión y dictadura tienen que ver con un mayor aplastamiento de los derechos indígenas, ¿por qué será?: la revolución de 1871, la invasión estadounidense de 1954, el fracaso del modelo de sustitución de importaciones y sus correlativas masacres. Necesitamos advertir que el campesinado indígena guatemalteco es parte de conglomerados diferentes, sus pueblos, y que sobre estos pueblos se enraíza toda una estructura de dominación. Necesitamos reconocer que las comunidades indígenas nunca han tenido paz, pues siempre han estado luchando para no morir de hambre y para no morir de no ser; que siempre han recurrido a las más diversas formas de resistencia, buscando cómo no estar sometidos. Necesitamos llamarlos pueblos y no sectores. Necesitamos verlos pueblos: idiomas, saberes, modos de producción y reproducción, historias, imaginarios que no son mestizos, que existen y enfrentan sus propias críticas y debates internos y conducen sus propios debates.

Para ser libres necesitamos reconocer su libertad. Las poblaciones indígenas campesinas han recurrido a luchas sindicales, luchas cooperativas, luchas gremiales y hasta a la insurrección local generalizada, con impacto nacional. Sus luchas siempre han sido territoriales y siempre han sido acalladas. Desde los años setenta hasta hoy hemos vivido una larga etapa de levantamientos campesinos, la mayoría indígenas, y eso se debe a que una y otra vez vuelven a imponerles estrategias que pretenden controlarlos y asfixiarlos. Este libro es un buen pre-texto para reflexionar qué tanto hemos avanzado en la consciencia de que somos una sociedad plurinacional, y que los caminos que inventemos para ser libres, sobre todo las mujeres, tarde o temprano tendrán que reconocer tan escondida y flagrante realidad.

Hay que leerlo, hay que hablar de lo que el libro habla. Gracias, Ricardo Falla. Gracias a Avancso y a las universidades y entidades que han tenido el valor de patrocinarlo. 